\title{
Aziz Ab'Saber e Os saberes Intelectuais nas Paisagens do Mundo
}

\author{
Manoel Fernandes de Sousa Neto ${ }^{1}$
}

Biografias são como curvas de nível, rios que meandram, seixos arredondados pelo entrechoque que se produz entre a força das águas e a dureza dos assoalhos fluviais e, nesse caso, as intempéries que conformam percursos não lineares de uma mesma vida servem a esse ondear de formas nas suas grandes mudanças e sutis permanências.

Aziz Nacib Ab'Saber, a exemplo das paisagens que vislumbrou olhar, mudou com elas, à medida que pode ver as formações paisagísticas que ainda não vira, ao encontrar os mestres de uma longa trajetória intelectual pelo mundo, ao indagar sobre os processos que desconhecia entre as gentes de vida simples que habitava desde as margens dos rios amazônicos às extensas planuras secas dos pediplanos das depressões sertanejas do semi-árido nordestino.

Nascido filho "de Nacib da família Ab'Saber" em 24 de Outubro de 1924, veio a luz entre mares de morros naquela São Luis de Paraitinga onde as topografias se anelam suaves pelas formas mamelonizadas ou alaranjadas, só viu o mar do litoral paulista, de onde as escarpas abruptas o emparedam, ao descer com o pai no lombo do burro no interior de um jacás, ainda menino, e depois quando se tornara estudante da gratuita e pública Universidade de São Paulo e já homem feito buscava compreender os processos formantes das paisagens paulistas, brasileiras, mundiais.

A fala de Aziz tinha essa marca poética de tratar dos processos geomorfológicos, físicos, ambientais, ecológicos e naturais de maneira a torná-las suaves, desenhá-las diante de nós como a fumaça que brotando desse sopro de linguagem vai dissecando as formas, integrando os fenômenos, explicando os processos. Ao ouvi-lo é como se fôssemos vendo surgir diante de nós um quadro, uma fotografia, em uma construção imagética fenomenalmente didática. Vejamos como nos apresenta parte dos domínios dos "mares de morros" que acolheram suas visões desde a primeira infância:

"O domínio dos 'mares de morros' corresponde à área de mais profunda decomposição das rochas e da máxima presença de mamelonização topográfica em caráter regional de todo país. A alteração das rochas cristalinas e cristalofilianas atinge ai o seu maior desenvolvimento, tanto em profundidade quanto em extensão, chegando a ser enorme para diversos setores das regiões serranas acidentadas dos planaltos cristalinos do Brasil de Sudeste (núcleo sul-oriental do Escudo Brasileiro). É uma paisagem de forte expressão areolar, que se estende por algumas centenas de milhares de quilômetros quadrados, refletindo a ação dos processos morfoclimáticos tropicais úmidos em uma faixa hipsométrica cuja amplitude é superior a mil metros (pois a partir de dois a três metros acima do nível do mar, pode atingir até 1000 a 1100 m ou um pouco mais)" (2003, p. 57)

Uma outra de suas características metodológicas estava em não abrir mão da história para o entendimento dos processos geográficos, fosse ela história natural ou social, ao mesmo tempo que compreendia o conhecimento como algo que não era

\footnotetext{
${ }^{1}$ Professor Livre-docente da Universidade de São Paulo (USP). Email: manoelfernandes@ usp.br
} 
exclusividade dos intelectuais ou da universidade e que essas elaborações do mundo estavam, pois, presentes nas práticas culturais e sociais de diversos grupos étnicos e agrupamentos humanos.

Esta percepção multidisciplinar realizada a partir da geografia, o fazia mesclar diversas escalas espaço-temporais em seus sucessivos câmbios e longas permanências, para remontagem de quebra-cabeças que apareciam como imensos mosaicos que ele buscava integrar a partir de detalhes quase imperceptíveis, mas também de fenômenos de grande dimensão. Detalhes sobre os quais se indagava por longos anos, que por extensos períodos observava em diferentes lugares e que buscava compreender a partir de distintas apreciações interpretativas desde o que lia nos artigos, às coisas que ouvia dos mestres, às observações das pessoas mais simples.

Certa feita, em entrevista ao Programa Roda Viva em 1992, disse Aziz que a "observação exige um longo treinamento", porque observar repetidamente e indagar desde as rochas, as pequenas ravinas, às cornijas das cuestas, aos morros testemunhos, as correntes das águas que cruzam oceanos, as linhas de pedra era pois o andarilhar de olhos sobre as sutilezas complexas com que se costuma mirar para além do sensível no interior das paisagens. E Aziz observou muito e em muitos lugares. Esteve sempre atento ao que via e fez do mundo seu livro de cabeceira.

A opção pela Geografia ao invés da História veio, dentre outras coisas, da dificuldade daquele rapaz de poucos recursos financeiros que, tendo adentrado os portais da pública e gratuita Universidade de São Paulo, não tinha como adquirir livros ou revistas especializadas que eram caras e exigência fundamental para acompanhar a formação de historiador, como ele mesmo revela ao dizer:

"O preço dos livros de história e das assinaturas das revistas, especializadas era um empecilho. Nas primeiras excursões ao campo, descobri que na geografia eu podia ler a paisagem e não precisava de livros. E também não havia bibliografia para os trabalhos que deveríamos fazer. Bastava saúde e boa vontade. Comecei então a ir a campo e a fazer pequenas viagens. Como não tinha máquina fotográfica, aprendi a desenhar as paisagens que via." (1998, pp. 536)

O campo, foi nesse sentido, o lócus privilegiado do filho de Nacib, que explorava os arredores de São Paulo de maneira permanente, indo de trem aos subúrbios da cidade e andando a pé por longos trajetos, observando as formas que se esgrimiam entre a grande cidade em sua fabulosa fome por novas terras, vales de rios, áreas deprimidas e iam dando a dimensão clara das condições físicas existentes e do processo de ocupação sócio-histórica que se desdobrava por extensos territórios. Não por acaso, em 1956, do olhar de muitas colinas e sobre a sola de seus sapatos, elaborou sua tese doutoral "Geomorfologia do Sítio Urbano de São Paulo", que abre da seguinte maneira quando fala da "originalidade geográfica do sítio urbano de São Paulo":

"A originalidade geográfica principal do sítio urbano de São Paulo reside na existência de um pequeno mosaico de colinas, terraços fluviais e planícies de inundação, pertencentes a um compartimento restrito e muito bem individualizado do relêvo da porção sudeste do Planalto Atlântico Brasileiro.

De tal forma o esqueleto urbano e suburbano da aglomeração paulistana se justapôs à bacia sedimentar do alto Tietê, que o estudo do sítio atual da Metrópole equivale, sob muitos aspectos, a um estudo da própria região fisiográfica, restrita e individualizada, conhecida pela designação de bacia de São Paulo. Forçado por essa circunstância, o presente trabalhado compreenderá o estudo daquele patamar do Planalto Atlântico que se estende desde os 'altos' continentais da Serra do Mar até os 
sopés da Cantareira, do Jaraguá e do Itapetí, envolvendo a bacia sedimentar pliocênica e uma boa parte da bacia hidrográfica do Alto Tietê." (2007, p.13)

E saltar os olhos e observação dos limites de São Paulo, para os diversos ambientes naturais e humanos brasileiros, só foi possível, segundo o próprio Ab'Saber a partir de uma associação criada em 1934 pelos mestres franceses, dentre os quais destacamos Pierre Monbeig, e por colegas do curso de História e Geografia como Caio Prado Jr. Personagens com os quais pode conviver de perto aquele homem nascido "no entremeio de um mar de morros".

Aquela época a Associação dos Geógrafos Brasileiros (AGB), realizava seus eventos anualmente e por todo País. A cada encontro, geralmente em pequenas cidades, reuniam-se os geógrafos para ir a campo e realizar estudos que envolviam olhares diferentes sobre os mesmos espaços e paisagens e, dessa forma, elaboravam monografias que acabavam por ficar como contributos importantes aos locais de realização desses conclaves geográficos. Porém, mais do que as monografias eram capazes de deixar como herança, o fato é que a AGB funcionava como imensa e fabulosa escola pública a céu aberto e se constituía como lugar de grandes aprendizagens intelectuais.

Assim fala Aziz, da importância da AGB em sua formação logo depois de ter concluído a graduação:

"Entre 1944 - quando obtive o título de bacharel e me licenciei em geografia e história - 1965, tentei conhecer o Brasil, pois não tinha dinheiro para viagens mais longas e não havia auxílio de nenhum tipo. Tive a sorte de me filiar à Associação dos Geógrafos Brasileiros, que se reuniam uma vez por ano em pontos diversos do Brasil. A sociedade não se reunia em capitais, só em pequenas cidades e, durante essas reuniões, a gente aproveitava para fazer pesquisa de campo nos arredores. A sociedade foi fundamental na minha vida, porque, além de ter me permitido conhecer o Brasil, ainda me possibilitou publicar, em seu boletim, pequenas notas sobre áreas que percorria." (1998, 537)

É ainda, por intermédio dessas viagens proporcionadas pela $A G B$, que duas coisas nos possibilitam falar dos exercícios de método e das preocupações de Aziz como geógrafo.

Uma delas diz respeito a compreensão da extensão espacial dos fenômenos e a tentativa de estabelecer os grandes domínios da natureza no Brasil, para a partir de uma compartimentação geomorfológica muito criteriosa e respaldada em processos de observação, comparação, análise, pudesse então apreender conjuntos paisagísticos que conformavam unidades complexas derivadas de processos naturais e apropriações humanas comuns.

Não por acaso, o centro de sua observação atenta, era ocupado pelo problema das escalas espaço-temporais ou, dizendo de outro, admirava por quanto tempo e por que extensão territorial determinados fenômenos se estenderiam em seus desdobramentos diversos deixando, ainda que as escondidas ou sob o fogo dos pequenos detalhes, testemunhos residuais de eventos, marcas, processos pretéritos mais longos, extensos e intensos. Enfim, a lição de que o presente era a chave do passado e logo as paisagens da terra representavam um grande pergaminho palimpsesto.

A outra perspectiva de método, dizia respeito ao processo de comparação e se cunhava quase a partir de uma lógica que era perguntar: como se originaram as formas e ambientes terrestres que hoje vemos? Isso para, seguindo um interessante movimento, dizer que embora muitas coisas tivessem a mesma origem: geológica, 
climática, pedológica, hidrológica, botânica, era nas mudanças às quais haviam sido submetidas que cabia inquirir o que houvera feito se tornarem o que agora eram.

Um exemplo claro disso pudemos ter quando ouvimos, em um Congresso Nacional de Arqueologia realizado na cidade de João Pessoa, Aziz falando de algo que nos deixou a alma repleta de alegria naqueles idos de meados dos anos 1990 . Primeiro era um geógrafo falando para arqueólogos, depois falando de geomorfologia como quem proseia uma conversa doce na cozinha de uma compadre antigo e por fim, dizia respeito a algo sobre o que jamais havíamos pensado.

Naquele dia o filho de dona Juventina falou sobre serem primos próximos os Pães de Açúcar e os Inselbergs.

"As aplainações dos fins do Terciário pouparam massas de rochas resistentes, dando origem a inselbergs (serrotes) e cristas alongadas, algumas das quais cruzadas por gargantas (boqueirões). Esses, aliás, os únicos remanescentes a quebrar a monotonia relativa do vastos estirões das colinas sertanejas. Alguns agrupamentos de inselbergs, como os Patos (PB), os de Quixadá (CE), os de noroeste do Ceará ou ainda os de Milagres (no município de Amargosa, BA), constituem paisagens monumentais, dotadas de marcante individualidade. Para o interior do domínio semiárido, elas possuem o mesmo significado paisagístico dos pontões rochosos e dos pães-de-açúcar que despontam acima do nível dos morros florestados do Brasil tropical atlântico (Rio de Janeiro, Espírito Santo, nordeste de Minas Gerais). De certa forma os inselbergs são parentes dos pães-de-açúcar: nos períodos de incidência de climas secos em áreas hoje muito úmidas, sendo que os atuais pães-de-açúcar foram inselbergs. Por oposição, em velhas fases úmidas que precederam às aplainações dos fins do Terciário, alguns dos atuais inselbergs que pontilham os sertões secos podem ter sido pães-de-açucar." (1999, pp. 15 e 16)

O domínio do método, em larga medida aperfeiçoada a partir do contato com grandes mestres como Jean Tricart e entre as leituras teóricas testadas repetidamente nos trabalhos de campo, é que levaram Aziz Ab'Saber a deslindar os segredos que guardavam as muitas linhas de pedra (stone lines) que já houvera visto ao longo de sua vida em vários sítios brasileiros e que só conseguirá explicar indo a campo com alguém como Tricart, um dos grandes geomorfólogos que deu decisivos contributos teóricos à compreensão da gênese e morfodinâmica das paisagens.

O filho de Nacib teve contato com Tricart em evento da União Geográfica Internacional ocorrido em 1956 no Rio de Janeiro e a partir de então aprenderam um com o outro, a partir de uma profícua relação intelectual. Não é excusado lembrar que Jean Tricart era, à época, membro do Partido Comunista Francês e buscava entender de maneira mais dialética o processo de evolução das paisagens no jogo entre a resistência das antigas estruturas geológicas e da dinâmica que sobre elas aplicava as cambiantes condições climáticas na longa história da Terra.

É desse diálogo com outros intelectuais e cientistas que pode Aziz, contribuir com a elaboração de uma teoria que teve e tem destacado papel no sentido de explicar que condições outrora existentes podem voltar a ocorrer, remontando a partir de resquícios testemunhais o modo como os paleoambientes podem ser reconstituídos, explicando não apenas as suas formas, as espécimes que lhe habitaram, mas as culturas humanas que ai vicejaram em se tratando de períodos estratigraficamente passados e nesse processo, compreender o movimento das paisagens pretéritas.

"Já havia visto linhas de pedra dezenas de vezes no sul do país, mas não tinha condições de interpretá-las. Com o estímulo de Tricart, fixei-me na ideia de que as regiões com muitas linhas de pedra próximas umas das outras já teriam tido uma 
fisionomia semelhante à do Nordeste seco atual: com chão pedregoso e com áreas de solo sem pedra mas igualmente secas. Cheguei a fazer um mapa marcando todas as ocorrências de linha de pedra. Depois estabeleci os corredores que deveriam ter sido secos e comparei com as informações sobre a existência de brejos no Nordeste. Conclui que todas as áreas onde ocorria chão pedregoso tinham sido na verdade caatingas - e não cerrados ou cerradinhos - e que as matas recuaram para ambientes iguais aos brejos do Nordeste. Por aproximações sucessivas, cheguei à conclusão de que muitas áreas tiveram caatingas extensivas e as matas ficaram reduzidas a pequenas manchas em alguns pontos, que chamei inicialmente de 'redutos'. Mais tarde outros adotaram a mesma expressão. Por causa dessa conclusão, sou considerado um dos autores da chamada teoria dos refúgios. O 'jogo' que imaginei foi o seguinte: no momento em que as caatingas se expandiram, as florestas recuaram, mas não desapareceram, porque senão não teriam voltado. Esta foi minha maior intuição." (1998, pp. 539-40)

A elaboração dessa teoria permitiu a Aziz explicar a imensa instabilidade das biodiversidade amazônica, por ser extremamente recente do ponto de vista estratigrático e logo necessitando de políticas que garantissem a implementação de grande reservas de biodiversidade ali e na faixa atlântica brasileira, todas com datações do quaternário. $\mathrm{E}$, ao mesmo tempo, criticar políticas de expansão de uma agricultura e pecuária dura e próprias do agronegócio, que não respeitam nem os ambientes, nem as populações tradicionais que habitam estas áreas.

Ao se colocar dessa forma, Aziz propunha que pensássemos no futuro e, não apenas do Brasil, mas da humanidade. Por isso sua voz se levantou muitas vezes e em diversos lugares contra a construção de grandes usinas hidrelétricas na Amazônia, contra a razia que pode provocar o último código florestal que foi aprovado no parlamento brasileiro, contra a transposição do Rio São Francisco.

É possível dizer que aquele homem grande no tamanho, de gestos dóceis e sorriso fácil, que aglutinava centenas de estudantes bastava pisar o saguão do prédio da geografia e história, que gostava de polêmicas e não fugiu de expressar suas posições que há muitos desagradava, foi um dos melhores intelectuais que a Universidade de São Paulo pode formar e oferecer ao mundo.

Imagino se Aziz teria sido Aziz caso não pudesse, vindo das condições sociais de alguém sem recursos financeiros, provinciano caipira como ele mesmo dizia vez ou outra, tendo chegado a Universidade de São Paulo, enveredar no ambiente que Ihe permitisse dialogar com intelectuais de grande envergadura, encontrar as condições de viajar por todo Brasil, realizar de maneira pública as suas reflexões mesmo quando ainda um jovem intelectual.

A defesa da Universidade de São Paulo hoje, em meio a uma greve dura, em meio a um ataque sem igual à sua condição de pública, laica e gratuita, parece ser a melhor homenagem que se poderia prestar a mestres como Aziz Nacib Ab'Saber.

Aziz que se concebia como "um grande viajante e um aprendiz de geógrafo" $(1998,543)$, me fez sempre pensar que a boa ciência é aquela que nos permite ver o que ainda não víamos e intervir no mundo como não esperavam que fossemos capaz de fazer.

Creio que é tarefa nossa entregar melhorado tudo o que nos foi entregue, a herança de Aziz Nacib Ab'Saber e a USP que ele ajudou a construir faz parte desse espólio. Não abramos mão. 
Bibliografia

Ab'SABER, Aziz Nacib. Os Domínios da Natureza no Brasil. São Paulo, Ateliê Editorial, 2003.

Ab'SABER, Aziz Nacib. Entrevista ao Programa Roda Viva da TV Cultura, em 08 de Junho de 1998.

Ab' SABER, Aziz Nacib. Geomorfologia do Sitio Urbano de São Paulo. São Paulo, Ateliê Editorial, 2007.

Ab' SABER, Aziz Nacib. Cientistas do Brasil: depoimentos. São Paulo, SBPC, 1998. (852 p.)

Ab`SABER, Aziz Nacib. Sertões e Sertanejos: uma geografia humana sofrida. In: Dossiê Nordeste Seco. 